\title{
Parameter estimation of three-phase linear induction motor by a DSP-based electric-drives system
}

\author{
Nicolás Toro García ${ }^{1}$, Yeison Alberto Garcés Gómez ${ }^{2}$, Fredy Edimer Hoyos Velasco ${ }^{3}$ \\ ${ }^{1}$ Departamento de Ingeniería Eléctrica, Electrónica y Computación, \\ Universidad Nacional de Colombia Sede Manizales, Colombia \\ ${ }^{2}$ Unidad Académica de Formación en Ciencias Naturales y Matemáticas, Universidad Católica de Manizales, Colombia \\ ${ }^{3}$ Faculty of Science, School of Physics, Universidad Nacional de Colombia-Sede Medellín, Carrera 65 Nro. 59A-110, \\ Medellín 050034, Colombia
}

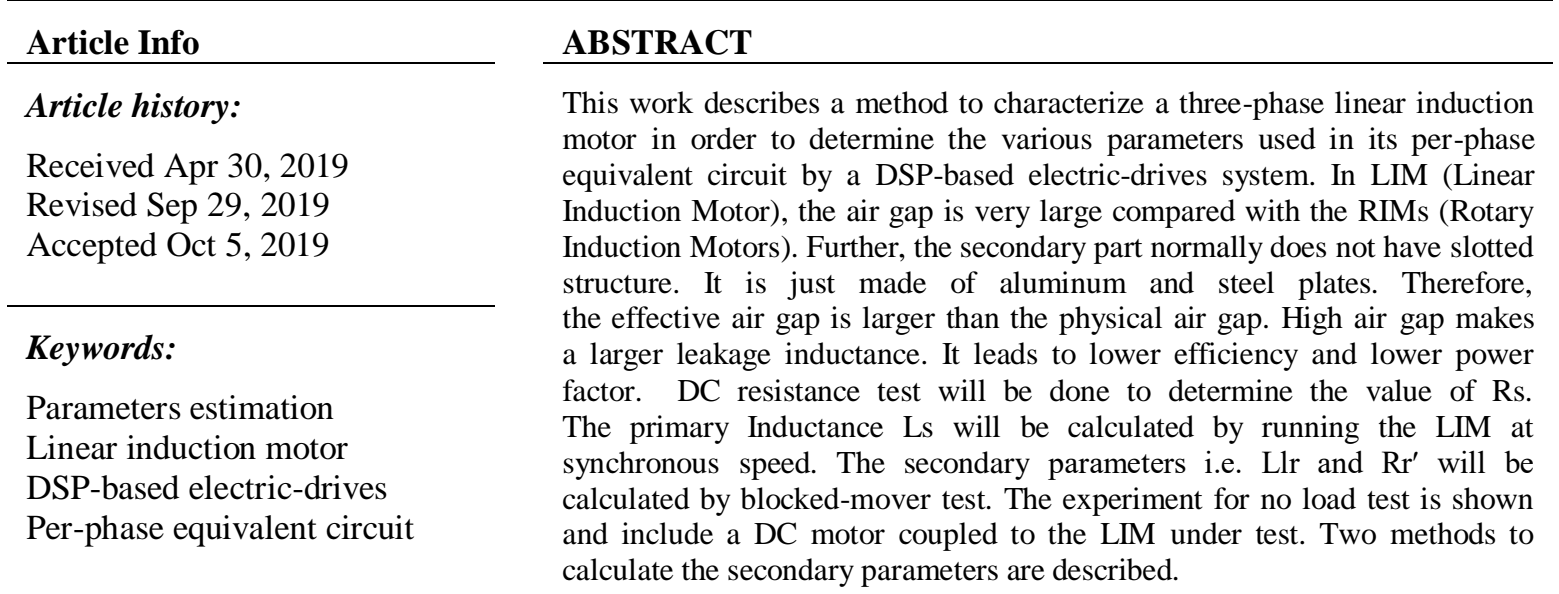

Copyright (C) 2020 Institute of Advanced Engineering and Science. All rights reserved.

\section{Corresponding Author:}

Fredy E. Hoyos Velasco,

Universidad Nacional de Colombia, Sede Medellín,

Facultad de Ciencias, Escuela de Física,

Carrera 65 No. 59A - 110, Medellín, 050034, Colombia.

Email: fehoyosve@unal.edu.co

\section{INTRODUCTION}

Although the linear motor was invented and patented more than a century ago, in the beginning it was impractical due to the difficulty of having a small air gap without roughness and with low power factor efficiency. However, technological advances have given the linear induction motor (LIM) greater importance at the academic and industrial levels, and its use has been extended in many applications [1-5]. Before the advent of linear motors, rotary motors with rotational-to-linear motion converters and with full mechanical transmissions were used to produce straight line movement. Using linear motors for applications that require linear motion eliminates gears and other mechanisms. The advantages of LIMs applied to linear movement are, among others, high capacity to perform acceleration and deceleration, ability to work in hostile environments, gears and mechanical transmissions are avoided, great ease of control of thrust and speed, existence of normal forces that can be used in levitation, low maintenance cost, low noise, great versatility in negotiating sharp curves and steep slopes, ability to exert force on the secondary without mechanical contact, movement and braking independent of the terrain, and low pollution [6-12].

The Lab-Volt Model 8228-02 is a Single Side Linear Induction Motor (SLIM) [13-15]. The stator is composed of a three-legged laminated iron core upon which are mounted three identical coils A, B, C. Each coil has 500 turns of No. 21 AWG copper wire, with a tap at 300 turns. The coils produce in each leg and corresponding salient pole, fluxes that are labeled $\phi_{a}, \phi_{b}$ and $\phi_{c}$. These fluxes are created by the currents 
$i_{a}, i_{b}$ and $i_{c}$ that flow in the respective windings; consequently, the fluxes are $120^{\circ}$ out of phase. This phase shift means that the fluxes attain their maximum value at different times, separated by intervals of $\frac{1}{3 f}$ where $f$ is the frequency of the source. If the phase sequence is $A-B-C$, flux $\phi_{b}$ will attain its maximum value $\frac{1}{3 f} S$ after $\phi_{a}$. Similarly, $\phi_{c}$ will reach its maximum value $\frac{1}{3 f} s$ after $\phi_{b}$. Then, the flux continually shifts from left to right across the face of the salient poles. If two of the supply lines are interchanged, the phase sequence will reverse, and the flux will shift from right to left across the poles. Knowing the distance $d$ between the centers of the poles, we can calculate the speed at which the flux moves. This is called the synchronous speed $v_{s}$ because it is directly related to the frequency of the power supply. The synchronous speed is given by:

$$
v_{s}=3 d f
$$

In the Model $8228, d=0,061 \mathrm{~m}$.

In this paper a three-phase linear induction motor will be characterized to determine the various parameters used in its per-phase equivalent circuit in Figure 1 by a DSP-based electric-drives system. The experiment is shown in Figure 2, where a DC motor is coupled to the LIM under test. There are five major components of the DSP-based electric-drives system, which will be used to perform the experiment. They are as follows: 1) Motor coupling system, 2) Power Electronics Drive Board, 3) Adjustable speed driver (ASD), 4) DSP based DS1104 R\&D controller card and CP 1104 I/O board [16, 19], and 5) MATLAB Simulink [20, 21] and Control-desk: 1) Motor coupling system, that contains the LIM that needs to be characterized [22]. The system has a mechanical coupling arrangement to couple LIM and DC motors [21]. The system also has a linear encoder mounted which is used to measure the position and the speed of the LIM. The motors demands controlled pulse-width-modulated (PWM) voltages to run at controlled speed. The PWM voltages are generated by Power Electronics Drive Board and Adjustable speed driver (subsequently described); the voltage sources thus generated are connected to the motor coupling system as shown in [22].

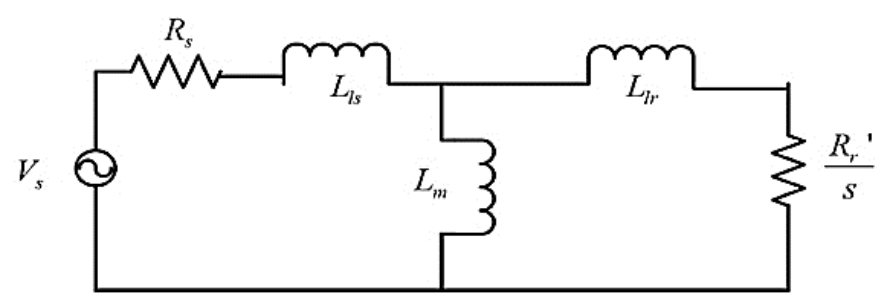

Figure 1. Per-phase equivalent circuit of a three-phase induction motor

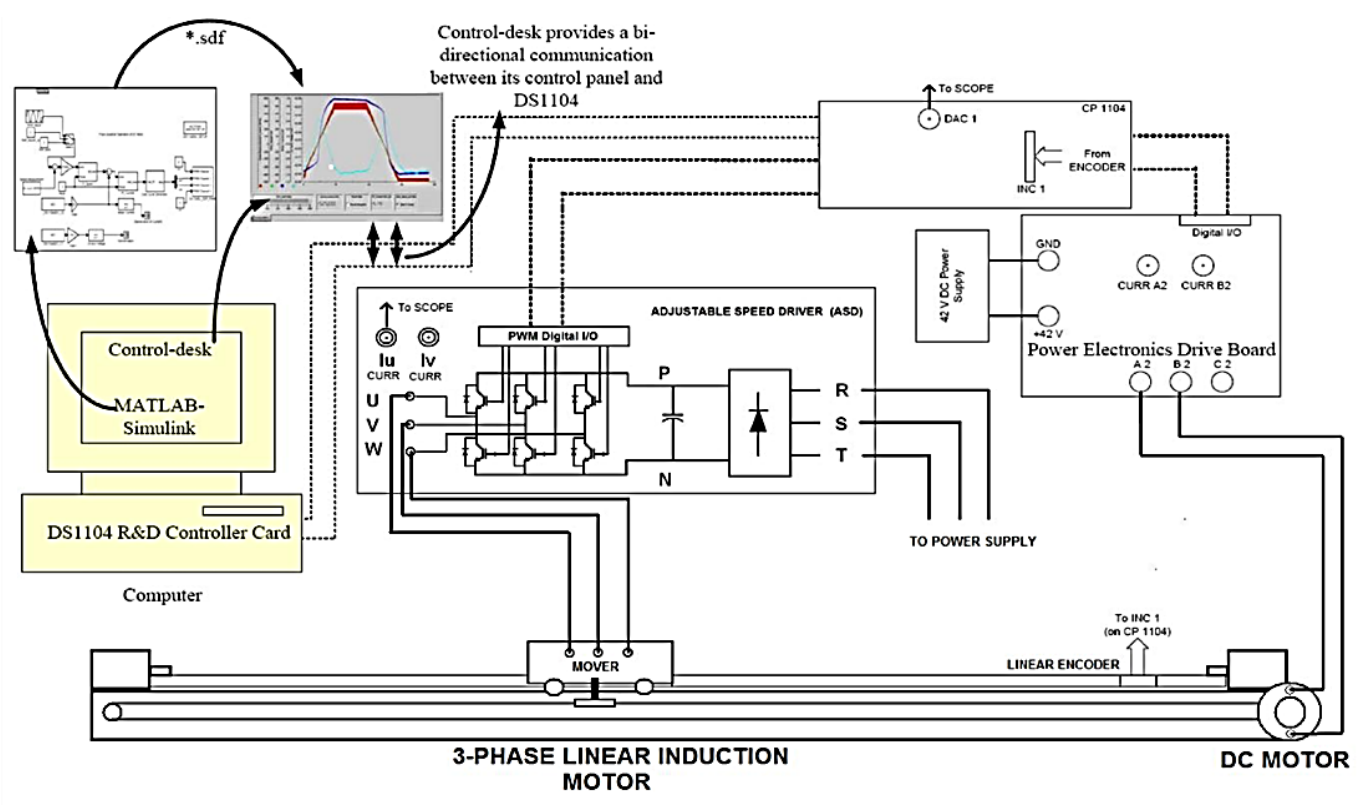

Figure 2. Experiment for LIM parameter identification 


\section{EXPERIMENT DESIGN}

The system for the speed of a DC motor and velocity and position of the LIM is shown in Figure 2. The encoder signal (speed and position of LIM motor) is fed back to the DS1104 board via CP1104 [23]. The $i_{v}$ phase-current and $d A$ duty cycle quantities are required to estimation of the LIM parameters. In the experiment, a Simulink model of a two pole DC switch-mode power converter will be built to control the voltage of the DC motor in real-time. The two-pole switch-mode DC converter voltage is the difference between the individual pole-voltages of the two-switching power-poles in Figure 3. The average output voltage $\bar{v}_{a b}$ can range from to $+V_{D C}$ and $-V_{D C}$ depending on the individual average pole voltages.

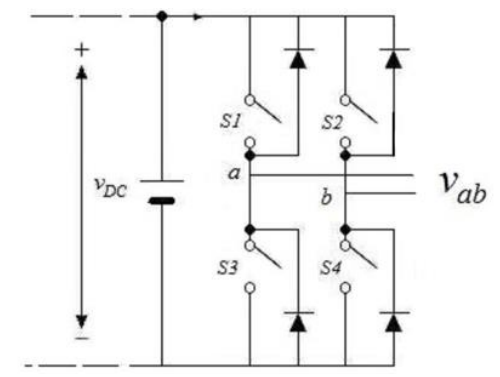

Figure 3. Two pole DC switch-mode power converter

To achieve both positive and negative values of vab, a common-mode voltage equal in magnitude to $V_{D C} / 2$ is injected in the individual pole-voltages. The pole-voltages are then given by:

$$
d A=\frac{1}{2}+\frac{1}{2} \frac{\bar{v}_{a b}}{V_{D C}} d B=\frac{1}{2}-\frac{1}{2} \frac{\bar{v}_{a b}}{V_{D C}}
$$

The above equation was implemented in Simulink. $d A$ Governs the duty cycle of the $S 1$ switch PWM and $d B$ governs the duty cycle of the $S 2$ switch PWM. Like was made earlier the PWM device was configured for center aligned PWM. Which forces symmetry about the center of the period. This configuration produces two pulses line-to-line during each period. The effective switching frequency is doubled, reducing the ripple current while not increasing the switching losses in the Power Electronics Drive Board.

A three-phase balanced voltage source of variable- magnitude and frequency is required, to run the linear induction motor at synchronous frequency. The duty ratios for the three poles $\mathrm{A}, \mathrm{B}$ and $\mathrm{C}$ to generate this type of voltage source are given by [24]:

$$
\begin{aligned}
& d_{a}(t)=\frac{1}{2}+\frac{1}{2} \frac{V_{m} \cos (w t)}{V_{\text {dlim }}} \\
& \left.d_{b}(t)=\frac{1}{2}-\frac{1}{2} \frac{V_{m} \cos (w t-2 \pi / 3)}{V_{\text {dlim }}} 4 \pi / 3\right) \\
& d_{c}(t)=\frac{1}{2}-\frac{1}{2} \frac{V_{m} \cos (w t-4 \pi / 3}{V_{\text {dlim }}}
\end{aligned}
$$

In (4) are modified form of (3) given in [24] which are suitable for real-time implementation.

$$
\begin{aligned}
& d_{a}(t)=0,5+0,5 u[1] \cos (\mathrm{u}[2]) \\
& d_{a}(t)=0,5+0,5 u[1] \cos (\mathrm{u}[2]-2 \pi / 3) \\
& d_{a}(t)=0,5+0,5 u[1] \cos (\mathrm{u}[2]-4 \pi / 3)
\end{aligned}
$$

where

$$
\begin{aligned}
& u[2]=2 \pi f t=\left(\frac{1}{s} f\right) 2 \pi \\
& s \rightarrow \text { Laplace Operator } \\
& u[1]=\frac{V_{m}}{V_{\text {dlim }}}
\end{aligned}
$$


There are various aspects to take into account in the experiment realization. One difficulty associated with the LIM is that due to the limit in the LIM stroke, is not easy to make a high speed no-load condition which is need for primary winding inductance estimation. To avoid such difficulty, we are considering to apply a lower frequency than the nominal frequency, and move the LIM in back and forth by DC motor at corresponding synchronous speed controlling its direction via the LIM position. The LIM movement is restricted between $0 \mathrm{~cm}$ and tope. To avoid sudden changes of reference speed in the motor a first order filter has been added. Sudden changes can cause high current peaks. In order to measure the LIM position and velocity the speedmeasuredc 2 simulink block was made. The linear encoder has a resolution of $20 \mu \mathrm{m}$ per channel thus the linear position may be in millimeters dividing the encoder counter value by 50 . It has a two quadrature channels, thus the accuracy is $5 \mu \mathrm{m}$. The control-desk panel for run the experiment is shown in Figure 4. The control-desk panel allow us to set the DC motor speed, LIM position limits and LIM frequency and monitors the duty cycles and LIM velocity in real-time.

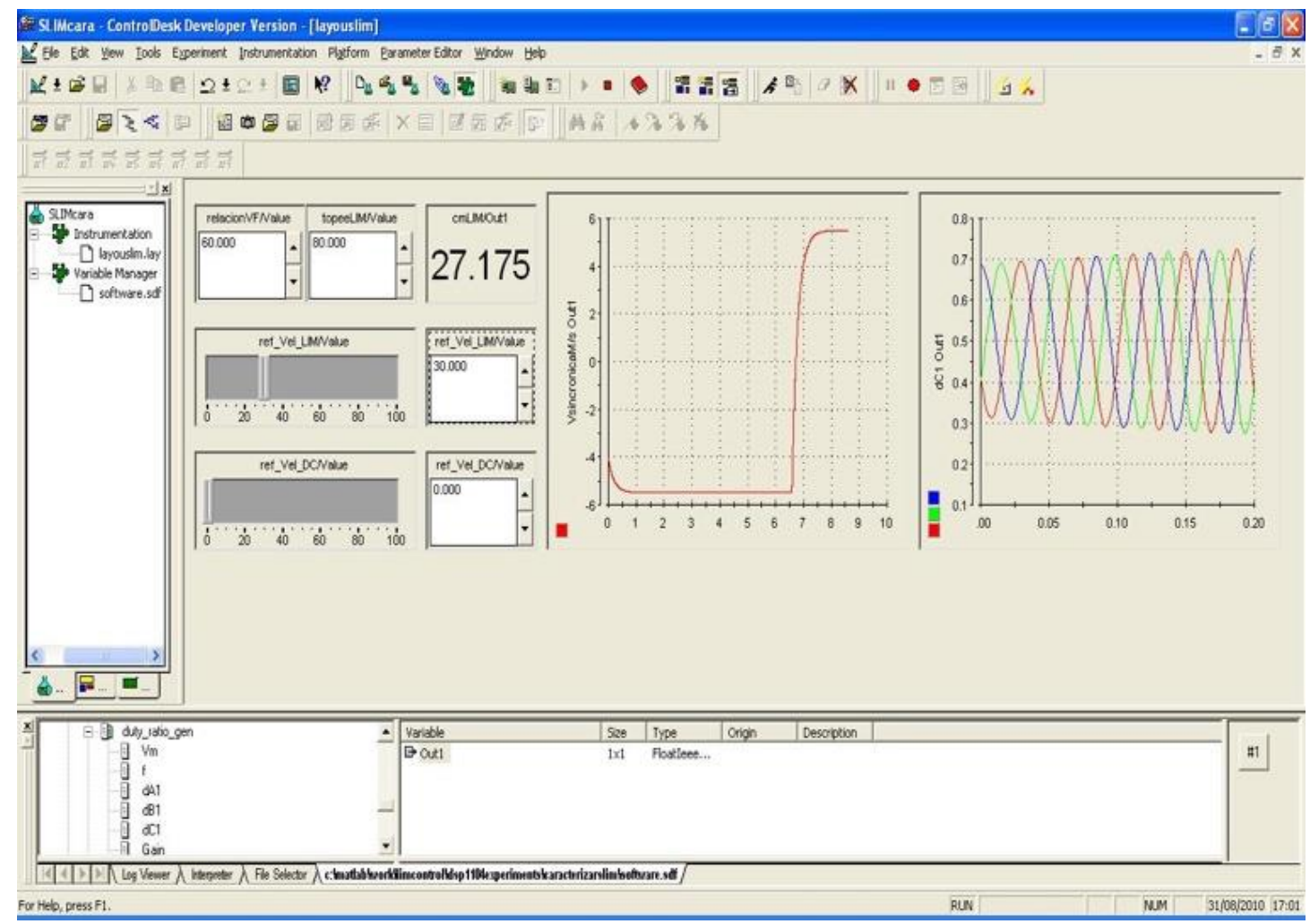

Figure 4. Control desk panel

To achieve no-load condition the LIM is feed with a lower frequency than rather frequency and via DC motor the system is moved at corresponding synchronous velocity. Since the secondary part of the LIM does not have slotted structure, the secondary leakage inductance is much smaller than the primary leakage inductance. Because of this, many parameter estimation methods of the RIM are not applicable to the LIM [25]. The mutual inductance $L_{m}$ will be calculated by solving a third order polynomial which will be derived from the total equivalent inductance [25]. Such method of obtaining $L_{m}$ directly allow us to calculate the leakage inductances of the primary and secondary windings separately and the secondary resistance.

\section{PRIMARI INDUCTANCE AND RESISTANCE ESTIMATION}

Primary resistance may be estimated by $D C$ current test. Applying constant line-line voltages $V_{u v}, V_{v w}$, $V_{w u}$, we can get generate $D C$ phase currents. Then, we obtain:

$$
\begin{aligned}
& R_{s 1}=\frac{R_{u v}}{2}=\frac{V_{u v}}{1 I_{u}}=1,6865 \Omega \\
& R_{s 2}=\frac{R_{v w}}{2}=\frac{V_{v w}}{1 I_{v}}=1,6680 \Omega
\end{aligned}
$$




$$
R_{s 3}=\frac{R_{w u}}{2}=\frac{V_{w u}}{1 I_{w}}=1,6900 \Omega
$$

Primary resistance is the average of $R_{s 1}, R_{s 2}$ and $R_{s 3}$

$$
R_{s}=1,6875 \Omega
$$

In estimating the primary inductance $L_{s}$, the secondary circuit should be seen as little as possible. To isolate the effects of the secondary circuit it is necessary to minimize the slip moving LIM at synchronous speed by DC motor. Then the LIM load is reduced. To reduce end effect, frequency $f=\omega_{e} / 2 \pi$ needs to be selected less than $18 \mathrm{~Hz}$, since end effect is negligibly small for $f<18 \mathrm{~Hz}[26,27]$. Under no load or a low slip condition, we can obtain from the Figure 1 an approximate equation such that:

$$
v_{s}=R_{s} i_{s}+j \omega_{e} L_{s} i_{s}
$$

Multiplying by $i_{s}$ and dividing by 2 both sides of before equation we obtain:

$$
\begin{aligned}
& \frac{v_{s} i_{s}}{2}=\frac{R_{s} i_{s}^{2}}{2}+j \frac{\omega_{e} L_{s} i_{s}^{2}}{2} \\
& V_{S_{r m s}} i_{s_{r m s}}=R_{s} i_{s_{r m s}}^{2}+j \omega_{e} L_{s} i_{s_{r m s}}^{2} \\
& S=P+j Q
\end{aligned}
$$

where $L_{s}=L_{l s}+L_{m}, \omega_{e}$ is the exiting angular frequency, $P$ is the active power and Q is the reactive power.

The experiment was made increasing the referen- ce frequency for the linear induction machine (by ref-Vel-LIM/Value slider in the Control-Desk panel) to $3 \mathrm{~Hz}$ corresponding frequency of the synchronous velocity and slowly increasing the DC motor speed to LIM mechanical synchronous velocity dictated by (1) (by ref-Vel-DC/Value slider in the Control-Desk panel), we obtained the LIM performance depicted in Figure 5 with $V s=0,549 \mathrm{~m} / \mathrm{s}$. The $V / F$ ratio and LIM stroke limit was settled in $300 \mathrm{~V} / 20 \mathrm{~Hz}$ and $100 \mathrm{~cm}$ respectively.

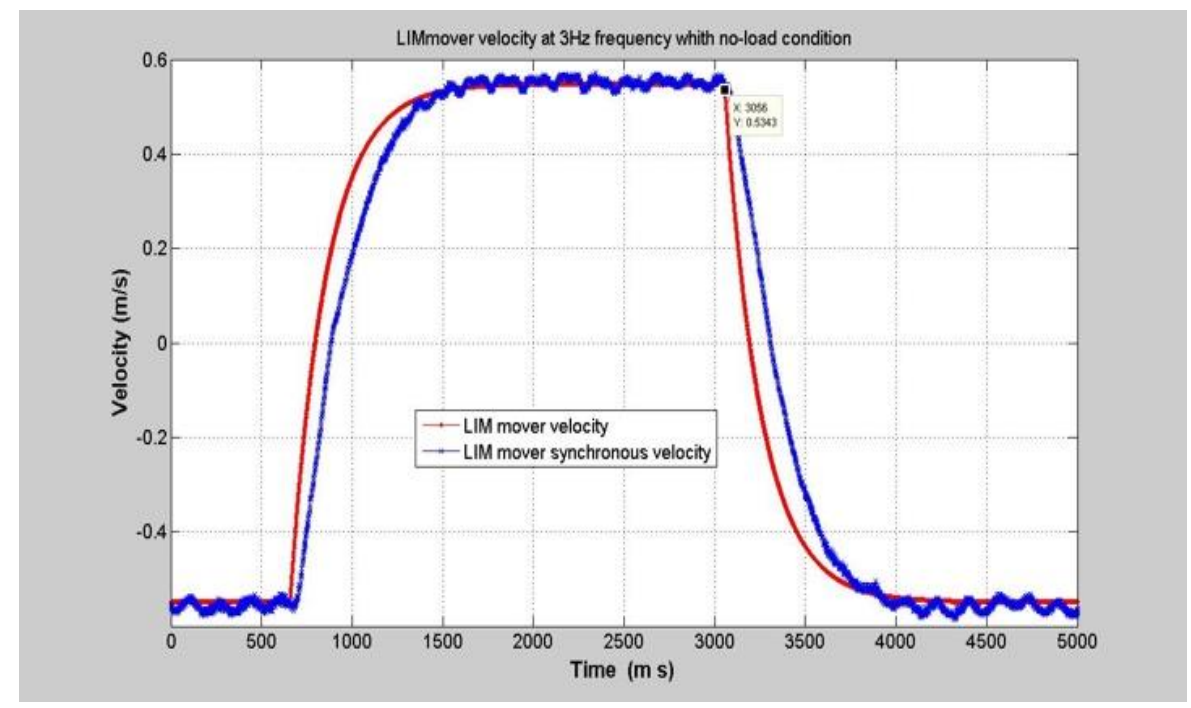

Figure 5. LIM mover velocity with no-load condition

Taking the waveforms for $\mathrm{dA}$ and iv on the oscilloscope as shown in Figure 6, we obtain the readings for the rms values of these variables. Also, we measure the phase difference between the two waveforms using the cursors. 


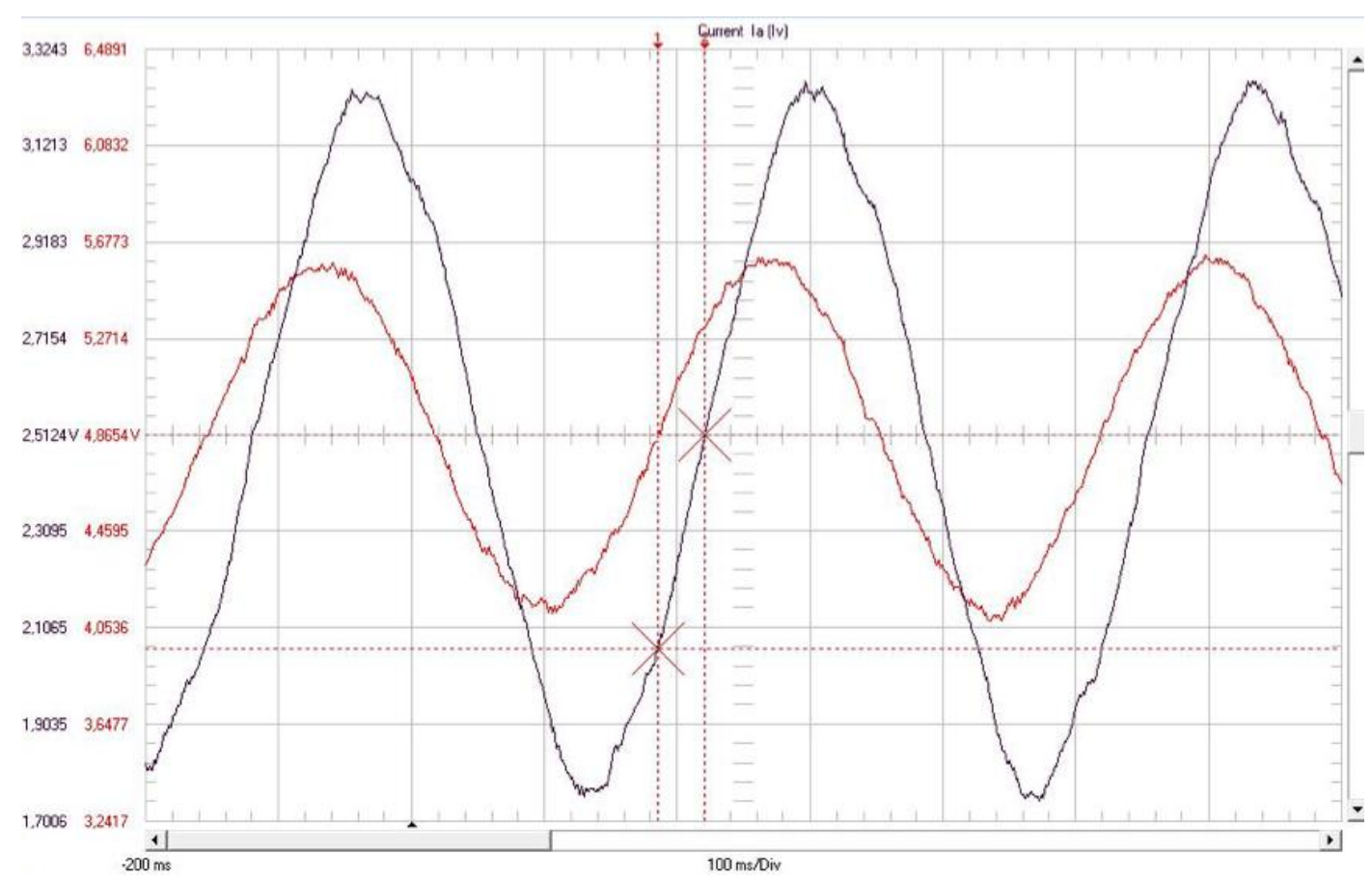

Figure 6. $V_{a}$ and $I_{a}$ wave forms with no-load condition

$$
\begin{aligned}
& d_{A, r m s}=0,053033 \\
& I_{A, r m s}=0,5356 \\
& \text { Phase }=\frac{35}{333,33} 360^{\circ}=\theta=37,8^{\circ}
\end{aligned}
$$

The scaling factor for $d A$ and $i_{v}$ are 10 and 0,125 respectively. Actual rms values of the phase $v$ voltage, phase $i$ current and the per phase reactive power drawn by the three-phase linear induction motor can be calculated as follows:

$$
\begin{aligned}
v_{v, r m s} & =d_{A, r m s} 300 \mathrm{~V} \\
& =\frac{d_{A, r m s}(\text { measured on the scope })}{10} 300 \mathrm{~V} \\
& =15,9099 \mathrm{~V} \\
i_{v, r m s} & =\frac{i_{v, r m s}(\text { measured })}{0,125}=4,2851 \mathrm{~A} \\
Q & =i_{v, r m s} v_{v, r m s} \sin \theta=41,7852 \mathrm{VAR}
\end{aligned}
$$

Where $\cos \theta$ is the displacement power factor.

This reactive power is consumed by primary inductance $L_{s}$ thus:

$$
Q=\omega_{e} L_{s} i_{v, r m s}^{2}
$$

$L_{S}$ can be calculated from the above equation.

$$
\begin{aligned}
L_{s} & =\frac{Q}{\omega_{e} i_{v_{r m s}}^{2}} \\
& =\frac{v_{v, r m s} i_{v, r m s} \sin \theta}{\omega_{e} i_{v_{r m s}}^{2}} \\
& =\frac{v_{v, r m s} \sin \theta}{\omega_{e} i_{v_{r m s}}} \\
& =120,7256 \mathrm{mH}
\end{aligned}
$$




\section{ESTIMATION OF $R_{e q}$ AND $L_{e q}$}

For obtaining the mutual $L_{m}$ and secondary inductances $L_{r}$, a large current must flow through the secondary circuit, i.e., current path through the secondary circuit must be dominant. To provide a large current flow through the secondary circuit, the mover-locked test is used. Since at standstill $v_{x}=0$ (mover velocity), the LIM equivalent circuit shown in Figure 7 can be represented as a series circuit, such that:

$$
Z_{e q}=R_{e q}+j \omega_{e} L_{e q}
$$

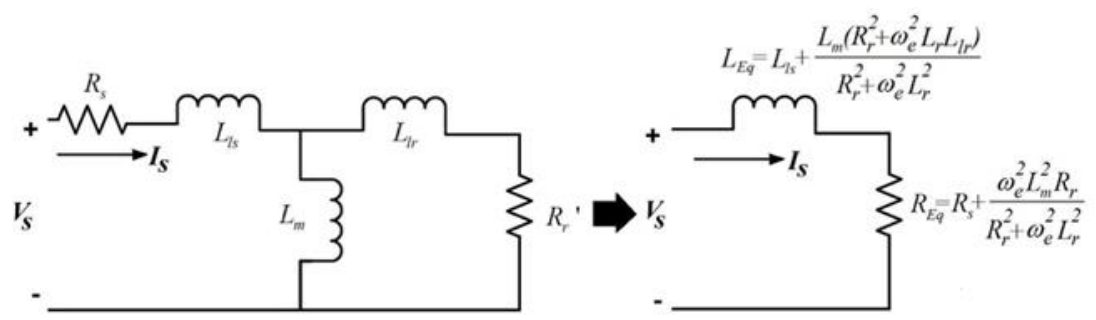

Figure 7. Equivalent circuit of a LIM at stanstill

$R_{e q}$ and $L_{e q}$ denote the total resistance and the total inductance and need to be estimated to obtain the estimates of the secondary parameters.

For $i_{-} s(t)=I \sin \left(\omega_{e} t\right)$, the $v_{s}(t)$ voltage is obtained in the steady state, such that:

$$
v_{s}(t)=R_{e q} i_{s}(t)+j \omega_{e} L_{e q} i_{s}(t)
$$

Multiplying by $i_{s}(t)$ and dividing by 2 both sides of before equation we obtain:

$$
\begin{aligned}
& v_{s_{r m s}} i_{s_{r m s}}=R_{e q} i_{s_{r m s}}^{2}(t)+j \omega_{e} L_{e q} i_{s_{r m s}}^{2}(t) \\
& S=P+j Q
\end{aligned}
$$

where $\omega_{e}$ is the exiting angular frequency, $P$ is the active power and $Q$ is the reactive power.

The experiment was made increasing the reference frequency for the linear induction machine (by ref-Vel-LIM/Value slider in the Control-Desk panel) to $30 \mathrm{~Hz}$ and locked the LIM mover. The $V / F$ ratio and LIM stroke limit was settled in $300 \mathrm{~V} / 60 \mathrm{~Hz}$ and $100 \mathrm{~cm}$ respectively. In the Figure 8 the experiment result is shown.

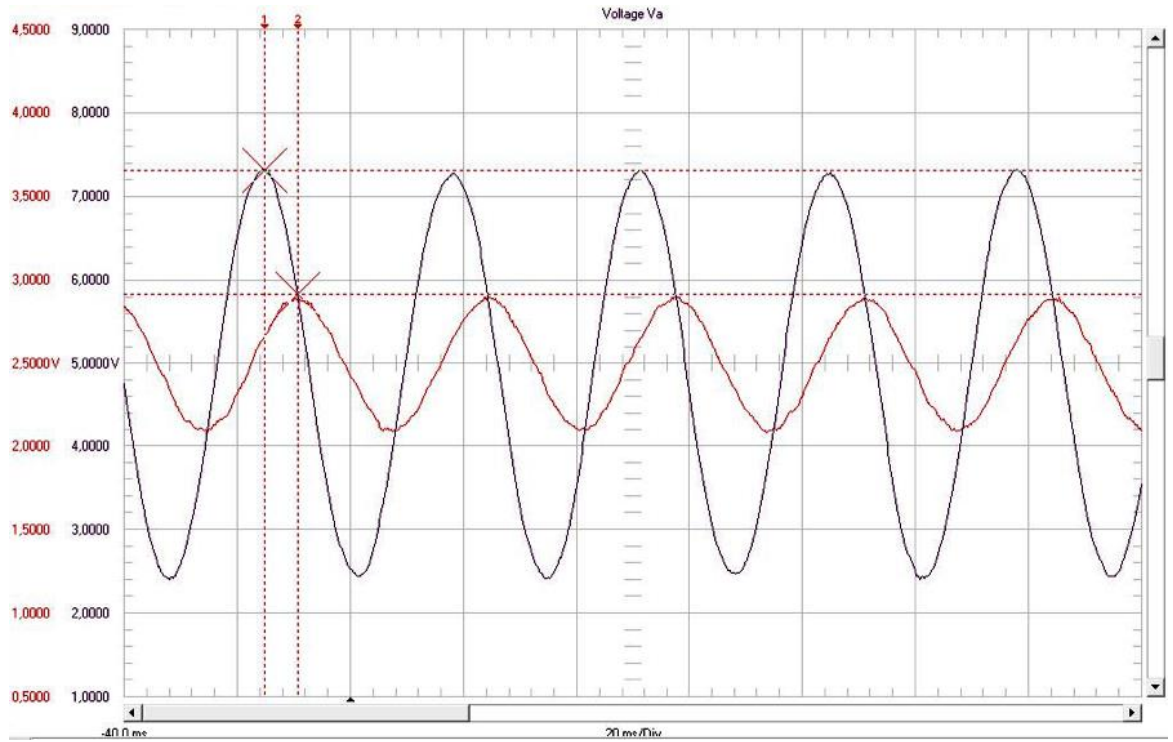

Figure 8. $V_{a}$ and $I_{a}$ wave forms in blocked-mover test 
The active power is $P=R_{e q} i_{s_{r m s}}^{2}=v_{s_{r m s}} i_{s_{r m s}} \cos \theta=53 V A$, and the reactive power $Q=\omega_{e} L_{e q} i_{s_{r m s}}^{2}=v i \sin \theta=112,6469 \mathrm{VAR}$ where $\theta=\arctan \frac{\omega_{e} L_{e q}}{R_{e q}}$, then,

$$
\begin{aligned}
& R_{e q}=\frac{P}{i_{s_{r m s}}^{2}}=9,62 \Omega \\
& L_{e q}=\frac{P}{\omega_{e} i_{s_{r m s}}^{2}}=108,4721 \mathrm{mH}
\end{aligned}
$$

\section{ESTIMATION OF $L_{m}, L_{r}$ AND $R_{r}$ FROM A THIRD-ORDER POLYNOMIAL}

Utilizing the estimated values, we define $\delta_{L}=\widehat{L}_{s}-L_{e q}$. We let $\beta=\frac{L_{m}}{L_{r}}$, which is unknown. Choosing $\omega_{e}$ high enough so that $R_{r}^{2} \ll \omega_{e}^{2} L_{r}^{2}$, one can approximate $R_{e q}$ and $L_{e q}$ from the circuit of the Figure 7 such that:

$$
\begin{aligned}
& R_{e q} \approx R_{s}+\frac{L_{m}^{2}}{L_{r}^{2}} R_{r}=R_{s}+\beta^{2} R_{r} \\
& L_{e q} \approx L_{l s}+\frac{L_{m}}{L_{r}} L_{l r}=L_{l s}+\beta L_{l r}
\end{aligned}
$$

Since $L_{s}=L_{m}+L_{l s}, L_{r}=L_{m}+L_{l r}$ and $L_{e q} \approx L_{l s}+\beta L_{l r}$, it follows that

$$
\begin{aligned}
& L_{l s}=L_{s}+L_{m} \\
& L_{l r}=\frac{L_{m}-\delta_{l}}{\beta} \\
& L_{r}=\frac{(1+\beta) L_{m}-\delta_{L}}{\beta} \\
& R_{r}=\frac{R_{e q}-R_{s}}{\beta^{2}}
\end{aligned}
$$

Note that $L_{m}$ is the only unknown value in the above definitions. Substituting (10), (11), (12), and (13) into $L_{e q}$ from the circuit of the Figure 7, we obtain a third-order polynomial for $L \_m$, such that:

$$
L_{m}^{3}+A L_{m}^{2}+\mathrm{BL}_{\mathrm{m}}+C=0
$$

where $A=-(1+\beta) \delta_{L} / \beta-\delta_{L} /(1+\beta), B=2 \delta_{L}^{2} / \beta, C=-\delta_{L}^{3} / \beta(1+\beta)-\beta \delta_{L} R_{r}^{2} / \omega_{e}^{2}(1+\beta)$. Note again that the coefficients $A, B$, and $C$ are available with the methods suggested above. The numerical solution of (14) is found by the solve function of MATLAB®.

Once $L_{m}$ is found, the estimates $L_{l s}, L_{l r}, L_{r}$, and $R_{r}$ are obtained directly from (10) to (13), respectively. $R_{r}$ is an intermediate estimate needed for deriving polynomial (14). Based on the estimates $L_{m}$ and $L_{r}$, we have a more accurate estimation method for $R_{r}$ than (14). Rearranging $R_{e q}$ in Figure 7, we obtain (15). The LIM parameters are showed in Table 1.

$$
R_{r}=\frac{\left(\omega_{e} L_{m}\right)^{2}-\sqrt{\left(\omega_{e} L_{m}\right)^{4}-\left(2 \omega_{e} L_{r}\left(R_{e q}-R_{S}\right)\right)^{2}}}{2\left(R_{e q}-R_{S}\right)}
$$

Table 1. LIM parameters

\begin{tabular}{cc}
\hline$R_{s}=1,6874 \Omega ;$ & $L_{m}=0,0420 \mathrm{H}$ \\
$L_{s}=0,1207 H ;$ & $L_{l s}=0,0788 H$ \\
$R_{e q}=9,6200 \Omega ;$ & $L_{l r}=0,0323 H$ \\
$L_{e q}=0,1085 H ;$ & $L_{r}=0,0743 H$ \\
$R_{r}=9,3720 \Omega ;$ & $R_{r, a d j}=3,9444 \Omega$ \\
\hline
\end{tabular}




\section{ESTIMATION OF $L_{m}, L_{r}$ AND $R_{r}$ FROM A THE EQUATION SYSTEM}

Knowing that $L_{s}=L_{l s}+L_{m}, L_{r}=L_{l r}+L_{m}$ and, substituting $L_{l s}$ and $L_{l r}$ into equation in Figure 7, the follow equation system is obtained:

$$
\begin{aligned}
& R_{e q}=R_{s}+\frac{\omega_{e}^{2} L_{m}^{2} R_{r}}{R_{r}^{2}+\omega_{e}^{2} L_{r}^{2}} \\
& L_{e q}=L_{s}-L_{m}+\frac{L_{m}\left[R_{r}^{2}+\omega_{e}^{2} L_{r}\left(L_{r}-L_{m}\right)\right]}{R_{r}^{2}+\omega_{e}^{2} L_{r}^{2}} \\
& \frac{L_{m}}{L_{r}}=\beta \Rightarrow L_{r}=\frac{L_{m}}{\beta}
\end{aligned}
$$

Since $L_{m}$ and $L_{r}$ are unknown, $\beta$ is also not known, it is around 0,95 in rotary induction motors, and 0,9 in linear induction motors. Giving a value to $\beta$, between 0,9 and 0,95 , the unknown variables are $L_{m}, R_{r}$ and $L_{r}$. Solving the system of the (16). The LIM parameters are showed in Table 2.

Table 2. LIM parameters

\begin{tabular}{rc}
\hline$R_{s}=1,6875 \Omega ;$ & $L_{m}=0,1704 \mathrm{H}$ \\
$L_{s}=0,1207 \mathrm{H} ;$ & $L_{l s}=-0,0497 \mathrm{H}$ \\
$R_{e q}=9,6200 \Omega ;$ & $L_{l r}=0,0148 \mathrm{H}$ \\
$L_{e q}=0,1085 \mathrm{H} ;$ & $L_{r}=0,1852 \mathrm{H}$ \\
$R_{r}=10,1666 \Omega ;$ & $R_{r, a d j}=10,1666 \Omega$
\end{tabular}

\section{CONCLUSION}

The electric parameters for a linear induction motor were determined in two ways. This parameters constitute the equivalent per phase electric circuit of LIM. The experiment for no-load and locked-mover test were designed using a DSP-based electric-drives system with two motors coupled, a DC Machine and a LIM. The control programs were made using MATLAB-Simulink of Matworks and Control- Desk of dSPACE. Adjustable Speed Driver was developed in the Universidad Nacional de Colombia - Manizales for the LIM control.

\section{ACKNOWLEDGEMENTS}

This work was supported by the Universidad Nacional de Colombia, Sede Medellín, grupo de investigación en Procesamiento Digital de Señales para Sistemas en Tiempo Real under the projects HERMES34671 and HERMES-36911, and the Universidad Católica de Manizales with the Grupo de Investigación en Desarrollos Tecnológicos y Ambientales GIDTA under the projec with the agreement 047 (18/Dec/2017) of the Governing Council. The authors thank the School of Physics for their valuable support given to the conduction of this research. This research paper corresponds to "programa reconstrucción del tejido social en zonas de pos-conflicto en Colombia del proyecto Modelo ecosistémico de mejoramiento rural y construcción de paz: instalación de capacidades locales," and is financed by the "Fondo Nacional de Financiamiento para la Ciencia, la Tecnología, y la Innovación, Fondo Francisco José de Caldas con contrato No 213-2018 con Código 58960." Programa "Colombia Científica".

\section{REFERENCES}

[1] I. Boldea and S. A. Nasar, Linear motion electromagnetic devices. Taylor \& Francis, 2001.

[2] I. Boldea and S. A. Nasar, "Linear electric actuators and generators," IEEE Trans. Energy Convers., vol. 14, no. 3, pp. 712-717, 1999.

[3] S. A. Nasar and I. Boldea, Linear electric motors : theory, design, and practical applications. Prentice-Hall, 1987.

[4] E. R. Laithwaite and S. A. Nasar, "Linear-motion electrical machines," Proc. IEEE, vol. 58, no. 4, pp. 531-542, 1970.

[5] C. NITUCA et al., "Thermal modeling of a linear induction motor used to drive a power supply system for an electric locomotive," Therm. Sci., vol. 23, no. 2A, pp. 589-597, 2019.

[6] G. Kang and K. Nam, "Field-oriented control scheme for linear induction motor with the end effect," IEE Proc. Electr. Power Appl., vol. 152, no. 6, p. 1565, 2005.

[7] Proceeding of International Conference on Electrical Machines and Systems 2007, Oct. 8-11, Seoul, Korea. IEEE, 2007.

[8] W. Xu et al., "Equivalent Circuits for Single-Sided Linear Induction Motors," IEEE Trans. Ind. Appl., vol. 46, no. 6, pp. 2410-2423, Nov. 2010. 
[9] Y. Du and N. Jin, "Research on characteristics of single-sided linear induction motors for urban transit," in 2009 International Conference on Electrical Machines and Systems, 2009, pp. 1-4.

[10] J. Faiz and H. Jagari, "Accurate modeling of single-sided linear induction motor considers end effect and equivalent thickness,” IEEE Trans. Magn., vol. 36, no. 5, pp. 3785-3790, 2000.

[11] I. Smolyanov, F. Sarapulov, and F. Tarasov, "Calculation of linear induction motor features by detailed equivalent circuit method taking into account non-linear electromagnetic and thermal properties," Comput. Math. with Appl., vol. June, 2019.

[12] F. Blaschke, "The principle of field orientation applied to the new transvector closed-loop control system forrotating field machines," Siemens Rev., vol. 39, pp. 217-220, 1971.

[13] I. Sijitha and S. Poorani, "Optimal design selection and analysis of single sided linearinduction motor," Int. J. Eng. Technol., vol. 7, no. 2.21, pp. 222-227, 2018.

[14] T. A. Lipo and T. A. Nondahl, "Pole-by-pole d-q model of a linear induction machine," IEEE Trans. Power Appar. Syst., vol. PASS-98, pp. 629-642, 1979.

[15] I. Boldea and S. A. Nasar, The Induction Machine Handbook; Electric Power Engineering. Boca Raton, FL, USA: CRC Press, 2002.

[16] M. L. Jurifa, I. Zulkifilie, M. Talib, A. Azrita, A. Nur, and M. Azri, "Speed and position estimator of for sensorless PMSM drives using adaptive controller," Int. J. Power Electron. Drive Syst., vol. 10, no. 1, pp. 128-136, 2019.

[17] S. Mensou, A. Essadki, I. Minka, T. Nasser, B. B. Idrissi, and L. Ben Tarla, "Performance of a vector control for DFIG driven by wind turbine: real time simulation using DS1104 controller board," Int. J. Power Electron. Drive Syst., vol. 10, no. 2, 2019.

[18] O. M. Arafa, M. E. Abdallah, and A. A. Ghada A., "Frequency adaptive Sliding Fourier Transform for synchronizing VSI to the grid," Int. J. Power Electron. Drive Syst., vol. 10, no. 2, pp. 1034-1048, 2019.

[19] R. Marino and P. Tomei, Nonlinear Control Design. New York, NY, USA: Prentice Hall, 1995.

[20] O. A. Trujillo, N. Toro-García, and F. E. Hoyos, "PID controller using rapid control prototyping techniques," Int. J. Electr. Comput. Eng., vol. 9, no. 3, pp. 1645-1655, Jun. 2019.

[21] A. Rincón, F. Angulo, and F. Hoyos, "Controlling a DC Motor through Lypaunov-like Functions and SAB Technique," Int. J. Electr. Comput. Eng., vol. 8, no. 4, p. 2180, Aug. 2018.

[22] N. Toro-García, Y. Garcés-Gómez, and F. Hoyos, "Discrete and Continuous Model of Three-Phase Linear Induction Motors 'LIMs' Considering Attraction Force,” Energies, vol. 12, no. 4, p. 655, Feb. 2019.

[23] F. E. Hoyos, J. E. Candelo, and J. A. Taborda, "Selection and validation of mathematical models of power converters using rapid modeling and control prototyping methods," Int. J. Electr. Comput. Eng., vol. 8, no. 3, p. 1551, Jun. 2018.

[24] N. Mohan, T. M. Undeland, and W. P. Robbins, Power Electronics: Converters, Applications and Design, 3rd ed. New York: John Wiley \& Sons, 2002.

[25] G. Kang, K. Junha, and N. Kwanghee, "Parameter estimation of a linear induction motor with PWM inverter," in IECON'01. 27th Annual Conference of the IEEE Industrial Electronics Society (Cat. No.37243), 2001.

[26] J. F. Gieras, Linear induction drives. Clarendon, 1994.

[27] J. F. Gieras, G. E. Dawson, and A. R. Eastham, "A New Longitudinal End Effect Factor for Linear Induction Motors," IEEE Trans. Energy Convers., vol. EC-2, no. 1, pp. 152-159, 1987.

\section{BIOGRAPHIES OF AUTHORS}

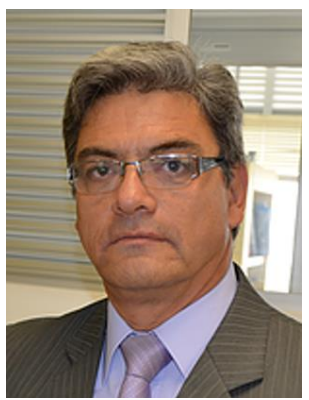

Nicolás Toro: received a B.S. in electrical engineering and Ph.D. in automatics from Universidad Nacional de Colombia, Manizales in 1983 and 2012, respectively, as well as an M.S. in production automatic systems from Universidad Tecnológica de Pereira, Colombia in 2000. He is currently an Associate Professor in the Department of Electrical Engineering, Electronics, and Computer Science, Universidad Nacional de Colombia, Sede de Manizales. His research interests include nonlinear control, nonlinear dynamics of nonsmooth systems, and power electronic converters. He is a member of the reasearch group in power resources GIRE (Código colombiano de registro: COL0144229), at Universidad Nacional de Colombia. https://orcid.org/0000-0001-8317-4126

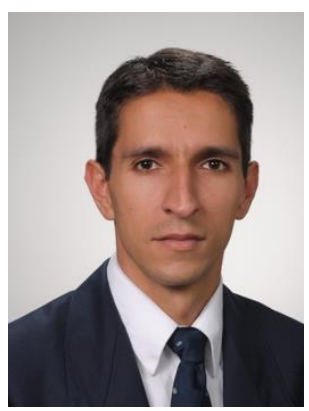

Yeison Alberto Garcés Gómez: received his BS and MS degree from the National University of Colombia, at Manizales, Colombia, in Electronics Engineering and Industrial Automation, in 2009 and 2011, respectively, and Industrial Automation Ph.D. in 2015. Dr. Garces is currently an Associate Professor of the Basic Sciences and Mathematics Academic Unit, at Universidad Católica de Manizales, at Manizales, Colombia. His research interests include power electronics, PQ, tecnologíes applied to education and medics, with application within a broad area of technological process. Dr. Garces is a Junior Researcher in Colciencias and member of the Research Group on Technological and Environmental Developments GIDTA at the Universidad Católica de Manizales. https://orcid.org/0000-0002-9409-3652 


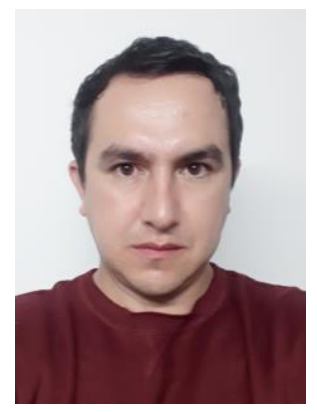

Fredy Edimer Hoyos: received his BS and MS degrees from the National University of Colombia, at Manizales, Colombia, in Electrical Engineering and Industrial Automation, in 2006 and 2009, respectively, and an Industrial Automation Ph.D. in 2012. Dr. Hoyos is currently an Associate Professor of the Science Faculty, School of Physics, at National University of Colombia, at Medellin, Colombia. His research interests include nonlinear control, system modeling, nonlinear dynamics analysis, control of nonsmooth systems, and power electronics, with applications extending to a broad area of technological processes. Dr. Hoyos is an Associate Researcher in Colciencias and member of the Applied Technologies Research Group (GITA) at the Universidad Nacional de Colombia. https://orcid.org/0000-0001-8766-5192 